\title{
Colegas do Silva: desempenho e vulnerabilidade dos homens em crônicas de Luis Fernando Verissimo
}

\author{
Silva's colleagues: men's performance and vulnerability in \\ chronicles by Luis Fernando Verissimo
}

\section{Luiz Carlos Simon}

Universidade Estadual de Londrina - UEL - Londrina - Paraná - Brasil

\begin{abstract}
Resumo: $\mathrm{O}$ artigo apresenta a análise de quatro crônicas escritas por Luis Fernando Verissimo - "A mulher do Silva", "Beijos", "A procura" e "A serenata" - todas incluídas no livro $A$ mulher do Silva, publicado em 1984. A análise é desenvolvida sob a perspectiva dos estudos das masculinidades. O objetivo do artigo é investigar como o desempenho e a vulnerabilidade, questões relevantes para o debate sobre as masculinidades, são focalizados nas crônicas selecionadas. $\mathrm{O}$ artigo estabelece as conexões entre os desempenhos dos homens representados nos textos literários e as discussões das questões nas contribuições teóricas sobre o assunto. A abordagem enfatiza a multiplicidade nos descompassos do homem em suas práticas sociais contemporâneas que envolvem as relações de gênero.
\end{abstract}

Palavras-chave: Homens. Masculinidades. Desempenho. Crônica. Luis Fernando Verissimo.

Abstract: The article presents the analysis of four chronicles written by Luis Fernando Verissimo - "Silva's wife", "Kisses", "The search" and "The serenade" - all included in the book Silva's wife, published in 1984. The analysis is developed under the perspective of the studies of masculinities. The aim of the article is to investigate how performance and vulnerability, relevant issues for the debate upon masculinities, are focused in the selected chronicles. The article establishes the connections between men's performances depicted in the literary texts and the discussions on the issues within the theoretical contributions on the subject. The approach emphasizes the multiplicity in the discompasses of men in his contemporary social practices which involve gender relations.

Keywords: Men. Masculinities. Chronicle. Performance. Luis Fernando Verissimo. 


\section{0 cronista Luis Fernando Verissimo e o Silva:} um padrão de masculinidade

Luis Fernando Verissimo transita com grande êxito no ambiente literário há mais de quarenta anos. Sua estreia em livro ocorreu em 1973, com O Popular, e sua carreira de farta produção de breves narrativas com ênfase no cotidiano prossegue até os dias atuais. Neste percurso, a circulação de seus textos em veículos da imprensa nacional com grande projeção, como Veja, Zero Hora, Jornal do Brasil, O Globo e O Estado de S. Paulo, ilustra a forte afinidade com o público leitor. As dezenas de títulos publicados - entre os quais se incluem $O$ analista de Bagé, Sexo na cabeça, A velhinha de Taubaté, A mãe do Freud e Comédias da vida privada - levaram à venda de mais de cinco milhões de exemplares, segundo dados fornecidos há mais de dez anos (GRAIEB, 2003). O sucesso do autor em jornais, revistas e livros estendese ainda para a televisão. As histórias de Verissimo foram adaptadas para minisséries e também estimularam sua atuação como roteirista de programas televisivos.

O sucesso do autor não se restringe aos campos comercial e midiático, mas pode ser localizado também no âmbito da intelectualidade brasileira. Podem ser citados prêmios e distinções relevantes em sua trajetória: o "Prêmio Direitos Humanos", concedido pela OAB, em 1989; o "Homem de Ideias do Ano", do Jornal do Brasil, em 1995; o "Prêmio Juca Pato", da União Brasileira de Escritores, em 1997; e recentemente, em 2013, seu livro Diálogos impossíveis the valeu o Prêmio Jabuti na categoria "Contos e crônicas" e foi ainda eleito o melhor livro de ficção do ano. Cabe ainda registrar que o cronista já foi incluído em duas histórias literárias brasileiras recentes. São alusões rápidas que confirmam, porém, a relevância do autor para o cenário literário e acadêmico. Ao concluir comentários sobre a obra de Erico Verissimo, Carlos Nejar ressalta que o autor de O tempo e o vento "legou a este país o seu grande cronista, entre o humor e a ficção, Luis Fernando Verissimo". (NEJAR, 2011, p. 541). Já Luciana Stegagno-Picchio, além de citar títulos de livros, refere- se a ele como "um grande cronista, autor de flagrantes cheios de atualíssimo humor brasileiro" e ainda qualifica as crônicas como "saborosas". (STEGAGNOPICCHIO, 2004, p. 646).

O Silva do título deste trabalho é o mesmo que aparece no título do livro de Luis Fernando Verissimo, A mulher do Silva, publicado em 1984. Como em outro volume do cronista publicado três anos mais tarde, $O$ marido do Doutor Pompeu, os títulos dos livros são os mesmos das crônicas homônimas em que os nomes próprios se referem aos protagonistas dos textos. Portanto, o Silva e o Doutor Pompeu, em suas crônicas, sobressaem como as personagens mais importantes, ainda que a "mulher" e o "marido", respectivamente, exerçam papéis fundamentais nas situações focalizadas.

O Silva é um homem atormentado pelas pichações que aparecem nas fachadas das casas de seus vizinhos de rua. Os motivos da perturbação são frases que levantam suspeitas sobre o comportamento moral da esposa do protagonista. A primeira pichação surge na casa em frente, do Souza. O Silva, sentindose ultrajado, atravessa a rua e exige que o vizinho apague a frase, passando tinta por cima. Após discussão e negociação entre os moradores - a casa era do Souza, mas a mulher era do Silva -, fica acertado que o marido "desonrado" custearia a pintura completa da casa pichada. O acordo incluiu ainda uma solicitação: "O Silva pediu que o Souza não contasse para ninguém.” (VERISSIMO, 1984, p. 20). Tudo indica, porém, que a reivindicação não foi atendida, pois, após a pintura da casa do Souza, outras casas da vizinhança, como as do Moreira e do Santos, passam a exibir frases alusivas à mulher do Silva, que se vê, então, forçado a pagar todas as pinturas. No parágrafo final da crônica, o narrador destila sua ironia diante da situação: "O quarteirão até ficou bonito, com as casas pintadas de novo. Algumas casas, é claro, ainda têm a pintura antiga. $E$ todas as manhãs o Silva as examina, prevendo o pior." (VERISSIMO, 1984, p. 20).

A personagem do Silva contribui para a composição de um retrato do homem que começa a ser esboçado no final do século XX e continua a ter 
retoques neste início de novo século. Diante da primeira pichação, a atitude imediata de Silva é de indignação, de honra ferida, mas o marido exaltado contém seus arroubos, afasta-se de qualquer ato mais violento ou assertivo contra o Souza ou contra a própria esposa e logo dá lugar ao negociador que se prontifica a financiar a pintura das casas dos vizinhos. Quando vê a terceira casa pichada, já não há sequer registro do sentimento de ultraje. Sua reação demonstra a vocação para negociar: "Já entrou direto na casa do Santos para combinar o preço." (VERISSIMO, 1984, p. 20). Antes disso, fica nítido que a personagem se perturba muito mais com os danos causados a sua própria imagem do que com a imagem ofendida e desrespeitada da esposa, pois o nome dela na frase pichada era omitido e substituído pela expressão "a mulher do Silva", o que agravava o efeito da injúria, segundo a perspectiva do protagonista. Por fim, as providências do Silva restringem-se à supressão das pichações na vizinhança, o que não é saída tão simples, pois as despesas com pinturas de tantas casas, com certeza, acarretariam 0 endividamento. Quanto à esposa, pivô da situação embaraçosa, não há qualquer movimento do protagonista para esclarecer se as frases pichadas correspondiam ou não às suas práticas.

Silva, com seu sobrenome comum, torna-se, portanto, representante emblemático dos impasses experimentados pelo homem contemporâneo. Ao discutir a atribuição de características femininas que qualificam o homem do final do século $X X$, Nolasco detecta a rede complexa em que se movem as marcas das masculinidades no presente: "A legitimidade da representação masculina associada a comportamentos de virilidade, posse, poder e atitudes agressivas se 'relativiza', abrindo frente a outras possibilidades de representação do homem." (NOLASCO, 1995, p. 19). O quadro focalizado pelo pesquisador já se define por um conjunto de traços em que determinados valores, como virilidade e agressividade, não se encontram mais como os únicos padrões que identificam práticas dos homens. Esta relativização de práticas tradicionais - posta deliberadamente entre aspas porque é objeto do questionamento do autor - não deixa de trazer alterações ou acréscimos para a discussão das masculinidades. Isso não significa reconhecer a virilidade ou a agressividade como etapas superadas, mas compreender que estes valores ora coexistem com práticas diferentes ora arrefecem. De qualquer modo, é necessário investigar com maior detalhamento o que são essas práticas e de onde elas procedem para que uma representação diferenciada do homem ganhe contornos mais nítidos.

Claudine Haroche, em vez de dar muito crédito a redefinições substanciais dos comportamentos dos homens contemporâneos, interpreta as associações da virilidade com o exercício de controle da vulnerabilidade e da impotência: "Os homens devem ser fortes, mais ainda, devem se mostrar fortes. Porém, considerados, ou se considerando como 'naturalmente viris', os homens temem acima de tudo serem descobertos na sua vulnerabilidade, serem reconhecidos na sua impotência." (HAROCHE, 2013, p. 29). A demonstração de força, nos homens, funciona, portanto, como uma precaução, uma estratégia prévia para impedir a descoberta da vulnerabilidade e da impotência que os acometem. Esse temor pode ser localizado na crônica "A mulher do Silva" através das intervenções rápidas do protagonista para apagar as pichações nas casas dos vizinhos, na irritação com a exposição do próprio nome nas frases e ainda no desejo de manter em segredo o acordo com o Souza. Em todas essas situações, a vulnerabilidade da personagem seria escancarada. Assim, Silva age para ocultá-la, embora sejam percebidas brechas em suas ações: além de nenhuma atitude ser tomada na relação com a esposa, os acertos com os vizinhos são meros paliativos que não - livram da tensão de descobrir novas pichações. Vestígios de virilidade comparecem, portanto, convivendo com a suspeita - ou mais do que isso - de uma fraqueza exposta tanto aos leitores quanto aos vizinhos, como denota a frase final da crônica: "Se bem que, segundo alguns, ele também devia vigiar a sua mulher". (VERISSIMO, 1984, p. 20).

O vínculo entre virilidade e vulnerabilidade como engrenagem que interfere sobre o desempenho 
dos homens está conectado ainda às especificidades das relações de gênero. Em sua análise das masculinidades, Connell sustenta que "é essencial reconhecer o dinamismo dos relacionamentos nos quais o gênero é constituído." (CONNELL, 2005, p. 38). A noção de dinamismo é fundamental para a compreensão da pluralidade dos homens que se materializa em desempenhos variados, que nem sempre repetem as expectativas e as práticas mais tradicionais. Essa variação decorre da manifestação de peculiaridades que, cada vez mais, são incorporadas aos relacionamentos entre os gêneros. Retomando a crônica, pode-se supor que, em tempos passados, talvez fosse mais incomum uma mulher casada ter comportamentos que suscitassem aquelas pichações e que fossem esperadas reações mais decisivas de um marido exposto a essa situação em sua vida conjugal. Assim como se pode pensar que hoje, mais de trinta anos após a publicação do texto, fazer aquele tipo de pichação seria um anacronismo e que um marido, em circunstâncias semelhantes, exibiria indiferença ou seria tão discreto quanto o Silva. Essas conjecturas reforçam o traço dinâmico das relações de gênero. No entanto, a crônica fornece poucas informações sobre os hábitos da mulher do Silva, e este, sem agir de forma drástica nem recorrer à violência, reforça a ideia de que a ênfase do texto é outra. Cabe, assim, procurar esse dinamismo e investigar como desempenho, virilidade e vulnerabilidade contracenam em outras crônicas do mesmo livro de Verissimo para que Silva não se apresente sozinho nesse painel e sim acompanhado de colegas.

\section{Mais personagens em descompasso: outros} desempenhos masculinos

A frase inicial da crônica "Beijos" antecipa muitas das experiências a serem enfrentadas pela personagem e questões que podem ser aproveitadas para o debate sobre as masculinidades: "Esforçava-se para ser um homem moderno, mas tinha dificuldade com o protocolo." (VERISSIMO, 1984, p. 40). Curiosamente, alguns anos mais tarde, Mara Barasch assim inicia suas reflexões sobre sexualidade e expressão do afeto na vida do homem: "Para integrarse no processo de modernidade [...], o homem vem pagando um preço muito alto, nem sempre condizente com sua vontade ou com suas condições emocionais e afetivas." (BARASCH, 1997, p. 95).

O que está em jogo tanto na crônica de Veríssimo quanto no artigo de Barasch é a integração do homem na vida moderna e o descompasso decorrente dos percalços que surgem nessa trajetória e das carências históricas do universo afetivo dos homens. A crônica focaliza 0 protocolo ali representado pelos beijos: a quem beijar, quantos beijos dar em cada pessoa, beijar ou não outros homens, cumprimentar com beijos na boca etc. $O$ homem chega a consultar a esposa para saber se deveria ou não beijar determinadas pessoas, mas era necessário agir de forma rápida, e os hábitos se modificavam: "Para simplificar, começou a beijar todas. [...] A quantidade era outro problema. Já tinha dominado os dois beijos, estava confortável com os dois beijos, quando a moda passou a ser três." (VERISSIMO, 1984, p. 40). O incômodo com a situação reflete a falta de ajuste do homem diante de práticas sociais contemporâneas. $\mathrm{O}$ fato de beijar todas as mulheres é destituído de qualquer carga erótica e também não corresponde a indícios de virilidade; a decisão de generalizar o beijo no contato com as mulheres é uma mera tentativa de reverter o desconforto de ignorar qual seria o cumprimento adequado. A dependência em relação à esposa confirma a desvantagem dos homens no acompanhamento desse protocolo e insinua, por extensão, que o desempenho masculino em situações mais complexas é ainda mais desastroso. A personagem confessa sua inabilidade: "O problema da vida, pensava, é que a vida não é coreografada." (VERISSIMO, 1984, p. 40). Essa ausência de coreografia deixa o homem desorientado e constitui metáfora da perdição masculina. O homem já não sabe como agir com as mulheres nem como manifestar o afeto, uma vez que o beijo é ao mesmo tempo forma de cumprimento social e expressão de carinho. Para a 
personagem, porém, o beijo não passava de símbolo de sua incompetência social.

O descompasso ainda aumenta à medida que novas práticas se instalam nas interações e viram moda: "Aí os homens começaram a se beijar. Tudo bem. Seu lema passou a ser, se me beijam eu beijo, mas não tomo a iniciativa. Sua vida social complicouse." (VERISSIMO, 1984, p. 41). Os beijos entre homens significam uma novidade a mais a ser incorporada aos rituais de convívio social. A frase "Tudo bem." remete ao esforço, à concessão do protagonista para se ajustar a uma coreografia instável e pouco nítida que assimilava movimentos cada vez mais estranhos a sua própria orientação. O lema do protagonista, calcado na ideia de não ter a iniciativa de beijar outros homens, representa, portanto, um lugar intermediário entre o respeito ao paradigma heterossexual - que se impõe como linha de conduta para os homens e desvaloriza todas as demais formas de sexualidade (WELZER-LANG, 2004) - e a tentativa de aderir a um formato diferente de masculinidade em sintonia com as práticas sociais contemporâneas.

O deslocamento experimentado pelo homem na crônica ainda atingiria o ápice com a introdução de mais um passo àquela coreografia: "Quando, no seu grupo, as pessoas começaram a se cumprimentar com beijos na boca, ele se desesperou." (VERISSIMO, 1984, p. 41). O desespero do protagonista resulta da incapacidade absoluta de processar todas as informações do dinâmico código dos beijos. Além da quantidade variável de beijos e da troca de beijos entre homens, surgiam agora os beijos na boca para complicar ainda mais o domínio do ritual. Numa festa de casamento, o protagonista embaralha definitivamente as convenções, que já eram em si desordenadas, e promove uma cena hilária: "Tomado de uma espécie de frenesi, depois de beijar uma fileira de conhecidos e desconhecidos, ele dobrara o padre pela cintura e o beijara longamente, como no cinema antigo." (VERISSIMO, 1984, p. 41). Ter beijado o padre na boca, reproduzindo cena romântica de cinema, é o auge do descompasso da personagem, que se mostra completamente aturdida e fora do seu tempo. $\mathrm{O}$ ato lhe vale as reprimendas da esposa, em maior afinidade com as coreografias em vigor do que seu marido.

Florence Tamagne, especialista em história da homossexualidade, sustenta que a "noção de masculinidade não para de ser redefinida por hibridismos sucessivos." Segundo a autora, um dos fatores dessa redefinição é a "apropriação de elementos associados à cultura gay pelas masculinidades heterossexuais". (TAMAGNE, 2013, p. 453). Na crônica, os hibridismos que redefinem as masculinidades são bastante evidentes. Os beijos, outrora símbolos da virilidade, da conquista amorosa, do ímpeto masculino e dos anseios eróticos dos homens, tornam-se para o protagonista motivo de grandes perturbações. Para um homem, beijar até poderia ter a conotação de carinho e ser um ato dirigido a outro homem, desde que este fosse um parente próximo. Na maioria das vezes, porém, o ato era associado com a atmosfera de desejo. O protagonista fica atordoado na crônica com a transformação dos usos e dos significados dos beijos. A partir de certo momento, contudo, as dimensões do ato já se encontram tão alteradas que a troca de beijos entre homens e a vulgarização do beijo na boca deixam de causar tanto estranhamento. O descompasso do homem representado na crônica é uma imagem da perda de estabilidade nas masculinidades, embora o clímax da cena do beijo no padre revele, através das reprimendas da esposa, que as convenções sociais ainda preservam limites e, por meio da pose cinematográfica conduzida pelo próprio protagonista, que nem todo distanciamento do padrão masculino corresponde a uma afronta espontânea a este padrão; pode ser também produto da inabilidade do homem na vida social contemporânea.

Na crônica "A procura", há novamente a presença de um casal, assim como ocorre em "Beijos" e em "A mulher do Silva". Entretanto, se nas crônicas já abordadas 0 foco era direcionado predominantemente para os homens, aqui há uma divisão das atenções entre os integrantes do par em questão, ainda que seja o homem aquele que se envolve nas situações centrais privilegiadas no texto. A atribuição de destaque ao desempenho da mulher é 
justificada pelo modelo da vida conjugal apresentado, como se percebe nas primeiras linhas da crônica: "Casal moderno. Tanto que competiam profissionalmente. Advogados, tinham escritórios separados." (VERISSIMO, 1984, p. 42). A representação de um casal que vive em condições supostamente iguais, ao menos no plano financeiro e profissional, já prenuncia o enfoque dos modos de agir do homem defrontado com um conjunto de experiências que constituem novidades em comparação com o gozo de privilégios da tradição patriarcal. O prosseguimento do texto conduz rapidamente à percepção de que as condições igualitárias não se restringiam ao âmbito do trabalho, mas eram aplicadas também ao cotidiano íntimo e às práticas sexuais do casal. Logo é apresentado o acordo definido por ambos: "fidelidade, sim, mas sem exagero. Se ela quisesse ter, como dizia, experiências extracelulares, tudo bem, desde que fosse discreta. Ele também." (VERISSIMO, 1984, p. 42). O fato de ser a fidelidade dispensável, segundo o acordo firmado pelo casal, pode criar a expectativa de que o homem não estará apto a suportar uma eventual infidelidade da esposa ou episódios de sucessivas relações extraconjugais mantidas por ela. Seria uma expectativa baseada no clichê do homem infiel em contraste com a resistência à imagem da mulher sobretudo se esta mulher for casada - que usufrui de ampla liberdade no campo da sexualidade. Ao mesmo tempo, pode-se imaginar que a vigência de igualdade na vida profissional abriria espaço para a promoção de equilíbrio em outras esferas da convivência conjugal, o que, no entanto, não garante êxito ao andamento desse processo de reciprocidades.

Barasch prevê a conexão entre o plano profissional e os domínios da intimidade: "Se ocorrem mudanças nas relações de trabalho e nos negócios, automaticamente se alteram as relações afetivas e, inconscientemente, os comportamentos direcionados para o amor e a vivência de prazer sexual." (BARASCH, 1997, p. 96). A noção de vínculos automáticos e/ou inconscientes entre 0 mundo profissional e as experiências íntimas esbarra nos condicionamentos de cada gênero e ainda nas formas com que cada indivíduo administra a possibilidade de superar eventuais empecilhos e problemas particulares. No entanto, já faz até parte do senso comum a ideia de que há um descompasso entre homem e mulher no que diz respeito à capacidade de acompanhar as mudanças sociais, assim como há um desequilíbrio entre o estado emocional do homem e a velocidade das próprias mudanças.

Sob perspectiva diferente, mas sem se descolar das peculiaridades contemporâneas, a historiadora Anne Carol, especializada em história da medicina, traz para o centro do debate a persistência da virilidade masculina no convívio conturbado com os anseios e as conquistas das mulheres no território das práticas da intimidade:

A imposição da virilidade se inscreve num mundo liberado e liberal no qual, estando banalizadas as relações sexuais, a 'extensão do domínio da luta' coloca em concorrência os homens com as mulheres, que têm uma vida sexual plural, experiências variadas e expectativas explícitas. (CAROL, 2013, p. 64).

O diagnóstico da autora acrescenta ao debate uma postura mais ativa tanto de homens quanto de mulheres: não se trata apenas de focalizar estratégias e capacidades de adequação de cada um à vida contemporânea, mas verificar como transcorre o confronto entre recursos intensificados, porém tradicionais, dos homens - a virilidade reafirmada - e as demandas das mulheres sustentadas por experiências cada vez mais irrestritas no âmbito da sexualidade.

De volta à expectativa gerada pelo acordo do casal na crônica, a aposta no fracasso tende a ser atrelada a algum deslize a ser cometido pelo homem. Isso se confirma na crônica, mas não da forma mais previsível, o que, aliás, poderia também ser esperado diante da leitura de um texto de Verissimo. O "problema" do marido não é a incapacidade de digerir as relações extraconjugais da esposa nem 0 descontrole de seu instinto viril que poderia levá-lo a querer competir com ela e superá-la em quantidade de relacionamentos nem, ainda, o fracasso de seu desempenho sexual diante da esposa ou das amantes. O fato é que ele desrespeita, segundo a perspectiva da esposa, alguma cláusula do acordo, provocando a ira 
da parceira. Ele ainda argumenta que a discrição teria sido mantida, mas a raiz do atrito é a amante ser um travesti, o que basta para tornar-se um escândalo quando a esposa descobre: "Você podia ter me poupado essa." (VERISSIMO, 1984, p. 42). Inicialmente ela se recusa a ouvir explicações do marido, não admite sequer que ele a toque e ainda deixa de lhe dirigir o olhar. Depois de um tempo, um dia ela ainda o interpela com rispidez: "Qual é a explicação? Hein? Me explica!" (VERISSIMO, 1984, p. 43). A explicação do marido vem sob a forma de descrição apaixonada da amante:

\begin{abstract}
É uma pessoa muito terna, muito simples, que faz tudo por mim. Montei um apartamento para ela. Ela passa o dia no apartamento, só pensando em coisas para me fazer feliz. Adora o trabalho doméstico. Cozinha que é uma beleza. Adora roupa de baixo bem rendada e perfume. Nunca discute comigo. É boba, frívola, vaidosa, e eu a amo. (VERISSIMO, 1984, p. 43).
\end{abstract}

Torna-se nítido o desacerto nas práticas e nas expectativas do casal. Enquanto a esposa se escandaliza com a notícia e se preocupa com o fato de que a notícia se torne pública e se transforme, por sua vez, em escândalo, o marido estava à procura de uma espécie de realização que, a princípio, entra em choque com seus métodos. De qualquer forma, sua concepção de felicidade materializa-se em um perfil de gênero que diverge daquele proporcionado por sua esposa. Ao ser questionado por ela sobre a causa de ele ter procurado um homem, ele responde: "Eu não fui procurar um homem. Fui procurar uma mulher. E finalmente encontrei." (VERISSIMO, 1984, p. 43). Com essa resposta, a personagem elege a figura desejada de mulher, minimizando a condição de travesti da amante. Poderia ser interpretado que esta realização com a amante corresponde à supremacia do gênero, enquanto construção cultural, sobre o sexo e suas determinações biológicas. No entanto, há outras considerações. A personagem do marido recusa-se a mostrar-se como gay: ele foi procurar uma mulher, não estava em busca de um homem; e alega ter encontrado uma mulher, sem reconhecer a amante como homem nem como travesti. Nesse sentido, a reivindicação de sua condição heterossexual é ostensiva e se presta a preservar uma normatividade que alija outras manifestações de masculinidades. Butler interpreta processos desse tipo como reflexos "de uma prática reguladora que busca uniformizar a identidade de gênero por via da heterossexualidade compulsória." (BUTLER, 2015, p. 67). A personagem ainda se mostra incapaz de confessar sua vulnerabilidade: é óbvio que há insatisfação com a vida conjugal, mas este sentimento não é admitido. Ao mesmo tempo, afirmar que estava à procura de uma mulher com perfil tão distante do da sua esposa significa atestar a inviabilidade de propor a si mesmo um compromisso para reconstruir sua masculinidade segundo um modelo mais liberal: a "mulher" procurada e encontrada the permitiria ser aquilo que o homem tradicionalmente sempre foi, uma espécie de rei a gozar de serviços e privilégios para seu próprio prazer. O homem, enfim, revela-se inapto para a igualdade e para o equilíbrio, abdicando da busca de novas possibilidades de ser homem.

A crônica "A serenata" traz um novo integrante para o painel de retratos dos desempenhos de homens, o último dos colegas do Silva a ser focalizado. Aqui voltamos a ter um protagonista com grande destaque, o Souza, que não é o vizinho do Silva nem possui a malícia de seu homônimo. A apresentação da personagem feita no início da crônica pelo narrador já aponta particularidades: "E era mesmo um tipo em extinção. Um galanteador. As mulheres não sabiam como reagir aos rapapés do Souza. Ficavam confusas quando Souza não apenas Ihes beijava as mãos como dizia: 'A seus pés'. Seria gozação?” (VERISSIMO, 1984, p. 50). Trata-se de uma personagem deslocada de seu tempo, um homem extemporâneo. A ideia de apresentá-lo como "um tipo em extinção" corresponde ao propósito de evidenciar como ele está distante do padrão que predomina em sua época. Assim, os atos da personagem exibidos como excentricidades jogam luz sobre os comportamentos correntes. Seus galanteios são palavras e gestos incomuns no contexto em que ele circula e provocam nas mulheres respostas discretas até pelo desconhecimento dos significados e das intenções. O texto esclarece, porém, que inexistem intenções veladas naqueles galanteios, que 
eles não constituem estratégias nem disfarces, como comprovam as mulheres que não resistiram ao "charme antigo" do conquistador e fizeram circular versões sobre os desdobramentos: "Depois contavam que o Souza não queria nada, queria mesmo era namorar, ir ao cinema e depois a uma confeitaria. $O$ Souza era esta outra coisa ultrapassada, um moço respeitador." (VERISSIMO, 1984, p. 50). A prática de promover a circulação de relatos sobre 0 relacionamento já é sintomática de uma concepção de intimidade que se abstém de resguardar sensações e se abre para torná-las públicas, de forma que os desempenhos sejam amplamente conhecidos, o que banaliza e vulgariza tanto os relacionamentos quanto as performances de cada indivíduo. Não querer nada, além de namorar, ir ao cinema e à confeitaria, indica 0 contraste entre o desempenho do protagonista e as expectativas mais frequentes em torno das práticas masculinas. Aliás, o namoro e as idas ao cinema e à confeitaria não se diferenciam do "nada", o que permite supor que, para se diferenciar do "nada", é necessário desvencilhar-se da condição de "respeitador" e do componente folclórico e pôr em cena a virilidade e o desempenho sexual.

O historiador Dominique Kalifa, ao interpretar as conjugações entre a virilidade, as masculinidades e 0 crime, aborda imagens valorizadas do homem: "É primeiro pela aparência e pela força física que se reconhece o homem. [...] A beleza do rosto ou dos traços é [...] totalmente acessória. Ela pode mesmo revelar-se embaraçosa ou suspeita." (KALIFA, 2013, p. 304). O retrato esboçado pelo autor prevê um perfil masculino muito diferente daquele propiciado por Souza na crônica. Os modos respeitosos e refinados do protagonista, de forma semelhante ao que se pode avaliar a respeito da beleza, estão muito mais próximos de causar embaraço e suspeita do que da exibição de força e potência, que funcionam, segundo o estudioso, como requisitos de uma imagem convincente de homem. É com este sentimento vago e de certo estranhamento que Laura entra em cena e reage ao soneto composto por Souza em homenagem a ela, assim que se conheceram: "Laura achou graça, fez um comentário qualquer - 'Legal' ou 'Falou' - e esqueceu. Mesmo porque não saberia o que dizer a um homem de cabelo engomado e casaco acinturado." (VERISSIMO, 1984, p. 50). Depois do primeiro soneto recebido de forma lacônica, outros são escritos e enviados juntamente com buquês de flores diários, sem interferir decisivamente sobre o desdém e a indiferença da "musa": "Mas Laura nada. Trabalhava, estudava, queria se formar em psicologia, tinha mais o que fazer. Que cara chato, era a sua única reação.” (VERISSIMO, 1984, p. 51).

Inconformado com o silêncio da amada e com a falta de repercussão para sua corte, Souza irrompe com uma ideia em sintonia com suas práticas anacrônicas: reunir amigos e fazer uma serenata após a meia-noite para Laura, que morava no oitavo andar de um prédio de apartamentos. A ideia avança e um quinteto musical se forma, apesar dos obstáculos previsíveis e das objeções e do descrédito dos amigos: "- Isso não se usa mais, Souza.[...] - Que horas vai ser o troço?" (VERISSIMO, 1984, p. 51). A inconveniência da ideia faz parte das advertências dos amigos, que demonstram tanta estranheza a ponto de se referir à serenata como "troço". Isso explicita o abismo entre os comportamentos masculinos retratados e o lugar destinado por homens contemporâneos a determinadas expressões de sensibilidade. As frases ditas pelos amigos são ainda significativas porque mostram que, mesmo tendo opinião muito diversa das ideias do protagonista, aceitam participar da serenata, o que reforça a singularidade dos galanteios de Souza. Contudo, como não poderia deixar de ser, a serenata fracassa. Mal se inicia, a polícia aparece e invade o edifício, julgando tratar-se de assalto. Tiros são disparados e atingem Souza perto do pulmão, o que leva à necessidade de hospitalizá-lo. O descompasso do protagonista é acentuado e concretizado sob a forma dos tiros que lhe ferem e o colocam em risco de morte. A vulnerabilidade está presente também nesse modelo antiquado de masculinidade, que guarda, através do episódio da serenata, semelhanças com uma espécie de heroísmo, muito tradicional no repertório masculino. Nem tudo, porém, está perdido, pois Laura, que na noite da serenata não percebera nem a homenagem nem o tiroteio, faz uma visita ao 
seresteiro baleado no hospital - mero protocolo, resultado de seu sentimento de culpa pelo incidente -, mas isso basta para reanimar o paciente, com dificuldade até para respirar.

$\mathrm{Na}$ apreciação da trajetória das masculinidades e suas possibilidades de transformação, Connell e Messerschmidt consideram o dinamismo das relações de gênero e projetam a ideia de "redefinições da masculinidade socialmente admirada" (CONNELL \& MESSERSCHMIDT, 2013, p. 263). Essa concepção, apoiada no otimismo dos autores, remete a um quadro em que diminuiria o impacto de demonstrações da virilidade como expressões típicas e necessárias dos homens. Nesse sentido, os galanteios do protagonista em "A serenata" poderiam deixar de ser recebidos como curiosidades, excentricidades ou como práticas pitorescas para obter melhor avaliação. No entanto, o apego excessivo a um modelo retrógrado, sem interseções com a vida contemporânea, tende a manter sua imagem de contraponto em relação a um perfil de masculinidade ainda muito identificado pela necessidade de ostentar um desempenho viril. Redefinir graus de avaliação social da masculinidade pode nem mesmo implicar necessariamente 0 abandono da virilidade, mas certamente requer a sintonia com expectativas de diversas naturezas que já se consolidaram no presente.

\section{Os colegas do Silva reunidos: vulnerabilidades masculinas evidentes}

O idealizador da serenata é o único homem solteiro entre os colegas de Silva que compõem a galeria de personagens aqui focalizadas. O foco sobre seus encantos por Laura e sobre o desejo de conquistá-la mantém a relevância do vínculo entre homens e mulheres na abordagem das demais crônicas. Mesmo em textos nos quais a vida conjugal está fora do centro das atenções - "A mulher do Silva" e "Beijos" -, as mulheres exercem papéis importantes para o desempenho dos homens: na primeira, são as pichações sobre a esposa que colocam a honra do marido em xeque; na segunda, a esposa é a referência do protagonista para tentar decifrar o código dos beijos. E em "A procura", a vida conjugal, tanto quanto as buscas extraconjugais ganham relevo e confirmam a mulher como o impulso para o movimento masculino. Pedro Paulo de Oliveira (2004, p. 176), ao comentar o trabalho do psicólogo Joseph Pleck sobre as masculinidades, reproduz - para depois contestar os pressupostos do autor segundo os quais "são as mulheres que devem dizer se o homem é ou não autenticamente viril.". A contestação decorre da leitura de que uma afirmação como essa serve de combustível para o discurso que torna o homem uma vítima. De algum modo, as crônicas selecionadas confirmam as mulheres como árbitros da virilidade masculina. Em "Beijos" e "A procura", há intervenções rigorosas das esposas que condenam, respectivamente, o beijo do marido na boca do padre e o caso extraconjugal com o travesti; em "A serenata", a indiferença de Laura é o índice da reprovação da abordagem pouco viril de Souza; e ainda em "A mulher do Silva", a esposa está fora da cena, entre outros motivos porque o marido prefere cobrar e financiar as pinturas das casas dos vizinhos, sem se dispor a confrontá-la. Ainda que as crônicas permitam essa leitura segundo a qual as mulheres se encarregam da validação da virilidade masculina, há diversos elementos que impedem a correlação entre os homens ali representados e a condição de vítimas.

O principal desses elementos é a exposição detalhada da vulnerabilidade. Victor Seidler (1989) associa a vulnerabilidade dos homens - que constitui, segundo ele, uma ameaça ao senso de masculinidade, na perspectiva dos homens - com a dependência e com a impossibilidade de reconhecer essa dependência nas relações estabelecidas com outras pessoas. Nesse sentido, a vulnerabilidade tende a ser sistematicamente silenciada. Assim, Silva interpela os vizinhos, mas não se dirige à mulher para averiguar os motivos das pichações; o protagonista de "Beijos" acaba por beijar o padre na boca para não deixar dúvidas sobre sua falta de habilidade nas práticas sociais; o marido de "A procura" é incapaz de verbalizar sua insatisfação na vida conjugal antes e depois de encontrar fora dela a "solução" de seus problemas; e Souza, em "A serenata”, providencia um 
discurso ultrapassado que não o livra do insucesso amoroso nem dos tiros. O desempenho masculino, assim, é comprometido pela revelação - e pelo medo da revelação - da vulnerabilidade e os evidentes descompassos que vêm em consequência. A reunião das crônicas aqui analisadas permite vislumbrar um painel destas vulnerabilidades e destes descompassos experimentados pelos homens e representados pela mordacidade do cronista. Ao ingressar nesse processo de desmascaramento do homem vulnerável, sem demonstrar qualquer compadecimento ou solidariedade, Verissimo contribui, com uma galeria de múltiplos perfis masculinos e, a partir de seus recursos cômicos, favorece o emprego de um olhar mais atento para discursos e práticas dos homens desde o final do século $X X$ até os dias atuais. Esta comicidade não só estimula o leitor a reavaliar as questões em torno das masculinidades, mas também constitui um formato de representação do homem mais afinado com as experiências sociais e as relações de gênero na contemporaneidade.

\section{Referências}

BARASCH, Mara. Sexo e afeto no cotidiano do homem. In: CALDAS, Dario (Org.). Homens. São Paulo: Senac, 1997.

BUTLER, Judith. Problemas de gênero: feminismo e subversão da identidade. 8. ed. Trad. Renato Aguiar. Rio de Janeiro: Civilização Brasileira, 2015.

CAROL, Anne. A virilidade diante da medicina. In: COURTINE, Jean-Jacques (Org.). História da virilidade. vol. 3: a virilidade em crise?. Trad. Noéli C. de Melo e Thiago A. L. Florêncio. Petrópolis: Vozes, 2013.

CONNELL, Raewyn. W. Masculinities. 2. ed. Berkeley: University of California Press, 2005.

CONNELL, Robert; MESSERSCHMIDT, James W. Masculinidade hegemônica: repensando 0 conceito. In: Estudos feministas. vol. 21. 2013.
GRAIEB, Carlos. O autor que é uma paixão nacional. Veja. São Paulo, n. 1793, p. 75-80, mar. 2003.

HAROCHE, Claudine. Antropologias da virilidade: o medo da impotência. In: COURTINE, JeanJacques (Org.). História da virilidade. vol. 3: a virilidade em crise?. Trad. Noéli C. de Melo e Thiago A. L. Florêncio. Petrópolis: Vozes, 2013.

KALIFA, Dominique. Virilidades criminosas? In: COURTINE, Jean-Jacques (Org.). História da virilidade. vol. 3: a virilidade em crise?. Trad. Noéli C. de Melo e Thiago A. L. Florêncio. Petrópolis: Vozes, 2013.

NEJAR, Carlos. História da Literatura Brasileira: da carta de Caminha aos contemporâneos. São Paulo: Leya, 2011.

NOLASCO, Sócrates. A desconstrução do masculino: uma contribuição crítica à análise de gênero. In: (org.). A desconstrução do masculino. Rio de Janeiro: Rocco, 1995.

OLIVEIRA, Pedro Paulo de. A construção social da masculinidade. Belo Horizonte: UFMG; Rio de Janeiro: luperj, 2004.

SEIDLER, Victor J. Rediscovering masculinity: reason, language and sexuality. London: Routledge, 1989.

STEGAGNO-PICCHIO, Luciana. História da literatura brasileira. 2. ed. rev. e atualizada. Rio de Janeiro: Nova Aguilar, 2004.

TAMAGNE, Florence. Mutações homossexuais. In: COURTINE, Jean-Jacques (Org.). História da virilidade. vol. 3: a virilidade em crise?. Trad. Noéli C. de Melo e Thiago A. L. Florêncio. Petrópolis: Vozes, 2013.

VERISSIMO, Luis Fernando A mulher do Silva. Porto Alegre: L\&PM, 1984. L\&PM, 1987.

O marido do Doutor Pompeu. Porto Alegre:

WELZER-LANG, Daniel. Os homens e o masculino numa perspectiva de relações sociais de sexo. In: SCHPUN, Mônica Raisa (Org.). Masculinidades. São Paulo: Boitempo; Santa Cruz do Sul: EDUNISC, 2004.

\section{COMO CITAR ESSE ARTIGO}

SIMON, Luiz Carlos. Colegas do Silva: desempenho e vulnerabilidade dos homens em crônicas de Luis Fernando Verissimo. Signo, Santa Cruz do Sul, v. 41, n. 72, out. 2016. ISSN 1982-2014. Disponível em: $<$ https://online.unisc.br/seer/index.php/signo/article/view/7180>. Acesso em: doi: http: //dx.doi.org/10.17058/signo.v41i72.7180. 